\title{
El Muntu en la literatura contemporánea: filosofía de la fuerza vital en Fe en disfraz (2009) de Mayra Santos-Febres ${ }^{1}$
}

\author{
Yaír André Cuenú Mosquera \\ Licenciado en literatura por la Universidad del Valle \\ Universidad del Valle, Cali, Colombia \\ https://orcid.org/0000-0002-0190-7275 \\ yaircuenu@gmail.com
}

\section{Resumen}

En Fe en disfraz (2009), de Mayra Santos Febres (1966), la autora presenta una representación de la espiritualidad ancestral que puede considerarse Muntu. Esta filosofía está constituida por diferentes maneras de concebir el mundo. A pesar de que, al arribo de las personas esclavizadas a América se transformara en un proceso de ocultamiento y sincretismo constante, el Muntu permanece de varias maneras en los pueblos negros de las Américas, principalmente del Caribe. Una de aquellas maneras es la fuerza vital, y leer Fe en disfraz desde este pensamiento nos permite comprenderla. Para desarrollar lo que afirmo, analizaré la ritualización que Fe Verdejo realiza en el acto de uso del vestido de la esclava Xica (Chica) da Silva, que, bajo la cosmovisión del Muntu y la perspectiva de la filosofía de la fuerza vital, crea en su propio cuerpo un canal de comunicación ancestral que expone la violencia con que se ha construido la identidad afrocaribeña.

Palabras clave: Muntu; afrocaribe; fuerza vital; Fe en disfraz, esclavitud.

\section{The Muntu in contemporary literature: Philosophy of La fuerza vital in Fe en disfraz (2009) de Mayra Santos-Febres}

\section{Abstract}

In Fe en disfraz (2009), by Mayra Santos Febres (1966), the author presents a representation of ancestral spirituality that can be considered Muntu. This philosophy is made up of different ways of conceiving the world. Despite the fact that the arrival of the enslaved people to America

\footnotetext{
1 Procedencia del artículo: Este artículo corresponden a la monografía para optar por el título de Licenciatura en Literatura, en la Universidad del Valle en 2018, titulado "Muntu en la literatura afrodiaspórica: la fuerza vital como espiritualidad en Beloved (1987) y Fe en disfraz (2009)". Particularmente el capítulo III de dicha monografía, titulado "El cuerpo del delito", presenta la reflexión correspondiente a Fe en disfraz.
} 
was transformed into a process of concealment and constant syncretism, Muntu remains in various ways in the black peoples of the Americas, mainly the Caribbean. One of those ways is the Fuerza vital and reading Fe en disfraz (2009) from this thought allows us to understand it. To develop what I affirm, I will analyze the ritualization that Fe Verdejo performs in the act of wearing the dress of the slave Xica (Chica) da Silva who, under the cosmovision of Muntu and the perspective of the philosophy of the Fuerza vital, creates in her own body an ancestral communication channel that exposes the violence with which the Afro-Caribbean identity has been built.

Keywords: Muntu; slavery; Fuerza vital; Fe en disfraz; Afro-Caribbean.

Recibido: 30 de abril del 2020. Hprobado: 21 de junio del 2020

Artículo de reflexión

https://doi.org/10.25100/poligramas.v0i51.10852

\section{¿Cómo citar este artículo en MLA? - How to quote this article in MLA?}

Cuenú Mosquera, Yaír André. "El Muntu en la literatura contemporánea: filosofía de la fuerza vital en Fe en disfraz (2009) de Mayra Santos-Febres" Poligramas 51 (2020): n. pag. Web.

Fecha de acceso (día, mes en mayúscula y abreviado, y año).

Contrario a lo que muchas veces se ha llegado a creer, la cultura no es singularidad inmutable, sino multiplicidad en constante transformación. Cuando repasamos la historia de la trata transatlántica, no estamos en una suerte de convención en la que cada forma de concebir el mundo decide qué elementos propios se integrarán a otra forma de pensamiento. No se trata de una negociación pacífica sobre qué ingredientes poner en la cocción de aquello que luego será llamado cultura. Al contrario, la violencia, la imposición, la desmembración epistemológica y el ataque a las memorias ancestrales son prácticas resultantes de aquella trata. Dinámicas como las anteriores, sumadas al enmascaramiento² (ese ocultamiento de aquella manera de

\footnotetext{
2 Parto de la propuesta de definición que da al concepto Rigoberto Banguero, quien lo presenta como un ocultamiento de las tradiciones ancestrales, en favor de su preservación. Se oculta bajo una supuesta aceptación de la religión impuesta, pero se rinde homenaje desde una real consciencia del origen ancestral.
} 
comprender el mundo), bajo la mimetización de la religión impuesta por los opresores, dan nacimiento al cimarronaje religioso.

Así, entonces, el sincretismo religioso nos presenta un escenario que exhibe historias de generaciones que se desarrollan en el limbo de lo irreconocible, buscando lo identificable y combatiendo por crear y construir puentes posibles con la memoria debilitada, frente a los sablazos de la trata y el inexorable paso del tiempo. Ha tomado años y años de luchas, choques de pensamientos, imposiciones y supervivencias, obtener algo que pueda denominarse un resultado de dicha confrontación-encuentro. Y sigue en construcción, sin embargo. Simple muestra es que haya casos en los que a una misma actividad se la pueda interpretar de formas antitéticas: por ejemplo, una ceremonia yoruba puede ser considerada como un acto profano de adoración maléfica, desde una perspectiva católico-cristiana, por mencionar alguna; mientras en la religión yoruba dicha ceremonia sería entendida como un ritual de ruego para recibir beneficios deíficos o agradecerlos.

Fe en disfraz, de la puertorriqueña Mayra Santos-Febres, es un perfecto ejemplo de la manera como la memoria se abre paso entre numerosos intentos por ser borrada, y recurre a la religiosidad, los símbolos y la representación espiritual, para ocupar un lugar en la comunidad. Este artículo se desarrollará teniendo como primer punto la definición del Muntu, refiriendo a la filosofía de la fuerza vital como expresión propia de dicha cosmovisión; posteriormente, resumiré Fe en disfraz, para luego adentrarme en el centro del análisis sobre las razones por las cuales esta novela contemporánea hace posible la comprensión del Muntu desde la perspectiva de la filosofía de la fuerza vital; finalizaré con unos breves comentarios. Empecemos por analizar la filosofía Muntu:

\section{El Muntu, filosofía de la fuerza vital}

La literatura es un arte cuyo tema principal es la condición humana. ¿Qué más humano que intentar reparar el puente roto con los ancestros mediante el hecho de otorgarles voz, vida y participación en el devenir de una comunidad? La representación de la espiritualidad en las comunidades negras aparece como un lazo intangible con el pasado, es sinónimo de la necesidad de sentir que se existe porque se tiene un pasado que así lo evidencia. Tras el desarraigo al que se vieron enfrentadas las personas en situación de esclavización, se formaron nuevas comunidades en lo que sería la diáspora africana. Desde el mismo viaje en los navíos 
negreros, las personas eran amontonadas y, además de recibir maltratos físicos, padecieron castigos psicológicos como separarlas de sus semejantes en lengua y cultura, y mezclarlas con otros grupos étnicos, de manera que se imposibilitara la comunicación entre los esclavizados. No obstante, el poder de la cultura permite que emerjan mecanismos de interacción humana que sobrepasan los límites que los opresores pretenden establecer.

Las gentes encontraron en su desastrosa condición de oprimidos un factor común: la empatía que produce encontrarse en una situación similar. Entonces la cultura empezó a obrar poniendo pequeños elementos que se convirtieron en campos de encuentro humano. Ejemplos de esto son los instrumentos musicales como el tambor ${ }^{3}$, que sirvieron de bandera para integrar los diversos grupos étnicos; también lo son las maneras de preparar algunos alimentos que, posteriormente, se convirtieron en referencias culinarias que irrumpían en las clases dominantes (Patiño), y concepciones del mundo que mezclaron lo mágico con la naturaleza y permitieron encontrar en los difuntos de la travesía un grupo de ancestros comunes que favorecerían el camino de la colectividad que seguía con vida ${ }^{4}$. Este último aspecto nos conduce al concepto principal que aquí se rastreará: el Muntu.

Las expresiones actuales de espiritualidad en las comunidades negras de la diáspora africana no son solamente un elemento que se origina en la situación de esclavización, sino también en diversas culturas africanas, como los bantús, dentro de las cuales existe la filosofía Muntu, en la que los ancestros difuntos ocupan lugares importantes dentro de la composición de la familia y comunidad tras su fallecimiento. La muerte es un nuevo estado y los difuntos toman lugares de privilegio, se convierten en oráculos que son consultados por la comunidad.

Antes de rastrear el concepto en la obra literaria referenciada, es necesario hacer una diferenciación entre la categoría Muntu y la filosofía Muntu. Para ello, nos resultan de fundamental relevancia los aportes de Diana Sierra Díaz en "El Muntu: la diáspora del pensamiento filosófico africano en Changó, El gran Putas de Manuel Zapata Olivella" (2016),

\footnotetext{
3 "Cuando los africanos esclavizados llegan a América, exploran diversas posibilidades sonoras, convirtiendo casi cualquier objeto en tambor y en motivación para el baile. A falta de espacios y materiales aptos para construir y tocar sus tambores originales, construyen unos más pequeños" (Barriga 30-48).

4 "En el contexto de la tradición oral, transmitido en su propia lengua o a través de la impuesta por el colonizador, el concepto de 'persona' integrada al ámbito 'familia' y al medio ambiente, concepto que no es otro que el que entraña la palabra 'Muntu', jugó indudablemente el papel de cohesionador de los pueblos dispersos en América" (Zapata Olivella 362).
} 
en relación con las contribuciones de Tempels, Jahn y Kagame. Este rastreo revisa primero la filosofía Muntu, de origen bantú, y finalmente las categorías que integran esta última.

Los bantúes constituyen un conjunto numeroso de grupos étnicos y de diversas lenguas provenientes de países como Angola, Camerún, República Democrática del Congo, Kenia, Mozambique, Sudáfrica, Uganda y Zimbabue, entre otros. Placide Tempels, autor de Filosofía bantú (1945), examina en su obra la manera como las lenguas bantúes se aproximan, señalando asimismo las semejanzas de las sociedades que las conforman tanto como de sus costumbres. La "filosofía bantú" o "filosofía Muntu" hace referencia al mismo concepto. Mientras que Placide Tempels se refiere a la "filosofía bantú", otros expertos como Jahnheinz Jahn o Fabien Eboussi Boulaga deciden simplemente llamar a esta "filosofía Muntu".

El Muntu como fuerza vital es uno de los puntos en común entre Tempels; Jahn y Kagame. En Filosofía bantú, Tempels aborda temas como la vida y la muerte, el culto al ser supremo y la ontología de los bantúes. Posteriormente, Janheinz Jahn y Alexis Kagame hablarán de una filosofía Muntu, constituida por las categorías Kintu, Kuntu, Hantu y Muntu. Dentro de este contexto, se considera el Muntu como una categoría que hace referencia al hombre, el Kintu a los animales tanto como los objetos, el Hantu a las categorías de tiempo y espacio, y, finalmente, el Kuntu se refiere a la forma de ser, al estilo y a la belleza 5 . Respecto a las categorías del Muntu, Jahn afirma que "fuera de ellas no hay nada imaginable" (Janheinz ctd. en Sierra 26-27).

Como menciona Sierra, hay una subdivisión del Muntu. El "concepto macro» es la filosofía Muntu (o filosofía bantú, según Tempels, aunque son lo mismo) que, a su vez, tiene categorías: Kintu, Kuntu, Hantu y Muntu. Al llegar a América, el hombre blanco pretende despojar a los pueblos negros de todo cuanto resulta visible. No obstante, es imposible borrar totalmente lo invisible: la concepción de mundo. Propongo una mezcla de las perspectivas de los autores anteriormente mencionados que se integre, a través de una definición suministrada por Manuel Zapata Olivella, al «concepto unificado»: por un lado, en Placide Tempels se refiere

\footnotetext{
5 "Las definiciones de estas categorías a partir de Jahn y Kagame son breves, y un tanto limitadas a nuestro parecer, dada la profundidad y complejidad de cada uno de estos ejes filosóficos. En este sentido, mencionaremos que el debate contemporáneo en torno a estas categorías se ha quedado en las definiciones presentadas en los años 1950 s sin ser complementadas por nuevos aspectos" (Sierra Díaz 26-27).
} 
directamente a aquellos aspectos a los que apunta esta investigación; es decir, la vida y la muerte y la ontología, en principio de los bantúes y, posteriormente, de los pueblos de la diáspora africana, donde se reconstruyen. Después están Jahn y Kagame, quienes coinciden con Tempels en un elemento que es transversal en sus definiciones: el Muntu como filosofía de la fuerza vital. Esta fuerza vital es potente aún en nuestra contemporaneidad y las construcciones de mundo en las obras referidas dan cuenta de ello. Ahora, doy paso a la definición «integradora» que aporta Zapata Olivella:

El Muntu concibe la familia como la suma de los difuntos (ancestros) y los vivos, unidos por la palabra a los animales, los árboles, los minerales (tierra, agua, fuego, estrellas), y las herramientas, en un nudo indisoluble. Ésta es la concepción de la humanidad que los pueblos más explotados del mundo, los africanos, devuelven a sus colonizadores europeos sin amarguras ni resentimientos. Una filosofía vital de amor, alegría y paz entre los hombres y el mundo que los nutre (362).

Manuel Zapata Olivella logra entregar una condensación de los teóricos antes referenciados y hace de la suya una propuesta integradora. Habla de "la familia como la suma de los difuntos (ancestros) y los vivos" (que se corresponde con Temples), "los animales, los árboles, los minerales" (Kintu), "los africanos, devuelven a sus colonizadores europeos sin amarguras ni resentimientos" (Hantu), "una filosofía vital de amor, alegría" (Kuntu), y, finalmente, el Muntu como categoría propia de la filosofía Muntu "paz entre los hombres y el mundo que los nutre" (Muntu) (362).

Muntu es un pasado y un nexo emocional y psicológico con los ancestros y las historias de esa comunidad a la que se pertenece de manera intangible, pese a las rupturas de los árboles genealógicos producidas por la esclavización. La literatura no ha sido ajena a este tipo de elementos culturales y narrativas como la de Mayra Santos-Febres (1966), entre otras cosas, alumna de Toni Morrison ${ }^{6}$, una maestra en la recuperación de la memoria de la diáspora africana en la literatura. Santos-Febres introduce la espiritualidad a través del relato de la historia de Fe Verdejo, historiadora negra venezolana que investiga la historia de esclavas negras

\footnotetext{
${ }^{6}$ Hago una revisión de las conexiones estilísticas e intelectuales entre ambas autoras en "Muntu en la literatura afrodiaspórica: la fuerza vital como espiritualidad en Beloved (1987) y Fe en disfraz (2009)", monografía con la que opté por mi título de licenciado en Literatura, en el 2018.
} 
latinoamericanas y, al hallar el vestido de una de ellas, experimenta un gran deseo de ponérselo. Cuando lo hace, acuden a su cuerpo un cúmulo de sensaciones que parecen retazos de su antigua dueña, despertando deseos sádicos y haciéndola percibirse a sí misma como una mujer diferente, atravesada por la sangre de aquellas figuras ancestrales. A continuación, presento un breve resumen de la obra que se tratará.

\section{Fe en disfraz (2009), Mayra Santos-Febres}

Esta poderosa novela relata la historia de Fe Verdejo, una mujer negra venezolana que investiga la vida de las mujeres esclavas en la Latinoamérica del siglo XVIII, a través de la recopilación y reconstrucción de datos encontrados en diferentes archivos, teniendo los diarios que pertenecieron a mujeres esclavizadas como su principal objeto de análisis. Su asistente es Martín Tirado, hombre mestizo que se siente atraído por ella y, además de ayudar con la sistematización de la información, prepara presentaciones multimedia que Fe utilizará en sus viajes a encuentros académicos. Uno de esos viajes la lleva a Brasil, donde encuentra el vestido de la esclava Xica da Silva, aquel con el que esta intentará ingresar a la sociedad blanca.

Xica da Silva es una figura mítico-histórica en Brasil de quien, quizá, se tienen más leyendas e historias populares que datos históricos constatables. Su popularidad radica en que se dice que ella, a través de su unión marital con un poderoso portugués, quien hacía parte del comercio de diamantes, logró unas condiciones de vida que incluían lujos como una mansión y muchas joyas. Sin embargo, investigadoras como Júnia Furtado han afirmado que en realidad esa parte de los lujosos es más un producto de la imaginación popular (Ruiza, Fernández y Tamaro 1).

Ahora bien, el vestido le produce una especie de atracción incontrolable, hasta el punto de que desea ponérselo. Al usarlo experimenta deseos sexuales sadomasoquistas que decide explorar con Martín. La investigadora pasa a ser también sujeto de su propia investigación, y de su cuerpo se apropia un poder superior que se relaciona con quien fuera la dueña del vestido para la época mencionada.

En este relato, el Muntu aparece en forma de ritual. La representación espiritual que, para efectos de este análisis, podríamos decir que corresponde a Xica da Silva, posee momentáneamente el cuerpo de Fe durante el acto sexual. Y, como menciono, podríamos adjudicar a Xica da Silva la presencia de esa fuerza vital que se apodera de Fe Verdejo, pero en 
realidad es una manifestación colectiva. No es la historia de un individuo en particular que se adentra en el ritual, sino de la fuerza vital de una colectividad. En este caso, una colectividad que refiere a las mujeres esclavizadas que, a través de su cuerpo, padecieron los vejámenes de aquel periodo histórico, sumado al de aquellas que hicieron de sus cuerpos un territorio de lucha mediante el cual combatieron sus condiciones. Todo esto entretejido en una propuesta narrativa donde destaca la combinación de datos reales (es decir, hechos históricos rastreables) con la ficción, produciendo un relato cuya verosimilitud hasta podría generar en quien lea un deseo de constatación.

La autora pone en el escenario el tema de la esclavitud en Latinoamérica y el Caribe; sin embargo, centra su interés en el cuerpo de la mujer negra como objeto de deseo, como llave para alcanzar una mejoría en las condiciones de vida, pero también como condena diaria de abusos padecidos por las esclavizadas. Es decir, hace del cuerpo de la mujer negra esclavizada un símbolo de sufrimiento, aunque también de resistencia, de violencia y también de persistencia. Esta historia se relata sobre el cuerpo de Fe Verdejo, que se convierte en mecanismo de sanación de heridas a través del sufrimiento y la posterior destrucción del vestido, que funge de objeto que da apertura al ritual de llamamiento del ancestro difunto (Banguero y Gruber 2-3). Ahora bien, pasemos a rastrear, con mayor profundidad, de qué manera puede percibirse el Muntu en Fe en disfraz.

\section{El cuerpo hecho rito}

Desde el principio de la novela atestiguamos las transformaciones que sufre Verdejo, quien tiene una relación de alto nivel académico con su asistente Martín, definido "algo así como un investigador virtual", en sus propias palabras, y con quien, además, sostiene algunos encuentros sexuales. En tanto avanza el relato, se nos revela una Fe que empieza a sufrir su primera gran transformación tras toparse con un valioso material textual que empieza a calar en su propio interior, afectándola en su condición de mujer, y mujer negra.

(...) dio con unos extraños documentos: declaraciones de esclavas con nombres en portugués y en español. Al principio, pensó que aquellos informes podrían ratificar la existencia de asentamientos que, quizás, dataran de los siglos XVIII o XIX. Pronto se dio cuenta de que se trataba de otra cosa. 
Algunos de aquellos papeles narraban cómo esclavas manumisas de diversas regiones del Imperio lusitano y del español lograron convertirse en dueñas de hacienda. Otros tan solo recogían testimonios de "abusos", en los cuales las esclavas pedían amparo real.

Encontró, además, documentos de condena por el Santo Oficio, declaraciones de tormentos y castigos. Mariana Di Moraes, Diamantina, la mulata Pascuala, los testimonios se sucedían uno tras otro. Relataban estupros y forzamientos con lujo de detalles. Su contenido sexual era particularmente violento (Santos-Febres 22).

Es importante anotar que la primera reacción que tiene Verdejo, ante este hallazgo, es sorpresa, que se fusiona con su consciencia del gran valor de aquellos documentos. En principio, su asombro se origina por un interés netamente académico, dado que aún no ha sido "tocada» personalmente por lo relatado en los documentos, pues recién empezará su análisis. A esta altura, la novela ya nos planteó el panorama: una investigadora negra especialista en recopilación de información y análisis de datos sobre la esclavización halla un tesoro académico: testimonios de esclavas abusadas por sus amos, condenas del Santo Oficio, y esclavas que se liberaron y se convirtieron en poseedoras de dinero. Desde luego, aún no hay muestra suficientemente evidente del Muntu.

La segunda transformación de Fe Verdejo viene de la mano del vestido que encuentra con unas monjas que dicen haberse enterado de su trabajo y tienen la voluntad de donar material para que sea investigado. Este es un momento clave, pues empieza a introducirse un aura de misticismo e imaginería que sirve de abrebocas al gran momento de ritualización y representación del Muntu en la obra. Con el vestido, que perteneció a Xica da Silva, arriban a su vida prácticas propias del mundo religioso y mágico del Muntu. ¿A qué me refiero? Lo primero que sucede cuando tiene el vestido en sus manos es que, por un lado, le es entregado por una monja que dice haberlo recibido de su madre, otra monja, quien, a su vez, lo recibió de su propia madre, monja también. De esta contradicción entre el mandato de la castidad y la evidente procreación le queda una sentencia: "Todas monjas y putas" (Santos-Febres 24).

Es importante mencionar lo anterior por varias razones: por un lado, la figura de monja, hija de ultrajes y violaciones de los mandatos de la iglesia que representan, está intrínsecamente relacionada con la vida de la propia Fe Verdejo, educada por monjas también. Es decir, ante Fe, la idea de llamarse «hermanas» resulta algo más que una categoría religiosa para referirse a esa 
comunidad, con la que tiene un punto en común. Por otro lado, no es casual que llegue de la mano de una monja. El acceso al mundo de los ancestros es realizado por personas con una especial destinación para tal fin. Como bien lo indica Pedro Gómez García en Mediadores e intermediarios. Sacerdotes, brujos y santones (1999), "la figura del mediador es fundamental en el sistema religioso de todas las sociedades humanas. Si la religión es siempre mediación, el mediador representa un exponente característico de cada sistema" (1). En este caso, si bien no es la monja quien se encarga de efectuar el proceso de ritualización, su figura se convierte en un elemento que nos permite comprender que en esa comunidad femenina religiosa es donde durante siglos ha reposado el objeto mediador. En la religión que, con recelo, guarda sus vergüenzas, se ha alojado durante siglos el testimonio de lo oculto.

Se convierten, entonces, estos mediadores en quienes abren las puertas a otros mundos. En este caso, esta religiosa blanca es una de las hijas del Dios católico y tiene permitido manipular objetos de poder espiritual que personas de otros niveles diferentes al suyo no podrían. Lo que abre la posibilidad a una pregunta interesante: si Fe Verdejo no es propiamente un "equivalente» de monja, ¿cómo es posible que se convierta en un conducto, un empalme, con el mundo de los ancestros?; es decir, ¿qué la «habilita» para tal fin? Más adelante abordaré las respuestas a esos interrogantes. Hay un detalle muy importante y que quizá pasa desapercibido: cuando Fe recibe el vestido le hacen una advertencia, se lo dan bajo una condición, y es importante recalcarlo porque en la magia suele ser común encontrar condicionantes a lo que se entrega. En los ritos casi todo lo que se hace tiene que llevarse a cabo bajo ciertas condiciones que, si no se cumplen, pueden convertirse en un castigo:

Fe se encaminó hasta la Hermandad y allí pasó semanas hurgando entre sus archivos. Se topó con más documentos de una esclava llamada Diamantina, con cartas firmadas por la Xica Da Silva (la Chica que Manda), de su puño y letra. En un ático escondido detrás de un techo falso, halló el vestido: arabescos bordados en hilo de oro, botones de madreperla, adornos dibujados en pedrería genuina. No le faltaba ni un encaje. Decidió ser arrojada; pedir permiso a las monjas para exhibir aquel tesoro en Chicago. Lo más seguro es que se negarían a su pedido, pero nada perdía con preguntar.

Para sorpresa de Fe Verdejo, las hermanas Macaúbas le concedieron llevarse el vestido. Así, sin más. No debía firmar seguros ni dejar cuantiosos depósitos. Tan solo tenía que cumplir con una condición. Las hermanas le pidieron que jamás devolviera el vestido 
a la Hermandad. Que se quedara con él, le buscara una mejor casa, un lugar donde pudiera sobrevivir a las liviandades humanas y a las del tiempo (Santos-Febres 24-25).

La única condición que le ponen para entregárselo es que no lo devuelva jamás a la hermandad. Pero además de eso, que busque una mejor casa, un lugar donde pudiera sobrevivir a las liviandades humanas y a las del tiempo. Esta última frase se presenta como una de las claves por descifrar. A Fe le está siendo entregado justamente lo contrario: se le entrega el peso, no la liviandad; es la carga de la esclavitud de sus ancestros que reposa en ese objeto que ha perdurado en el tiempo, lleno de heridas; le entregan el tiempo que encierra los espíritus de quienes poseyeron el vestido y a quienes el vestido poseyó.

Y esta última parte, la de la posesión, puede ser compleja si no recuperamos los conceptos de la filosofía Muntu. Tempels, cuando habla del Kintu, la categoría que integra la filosofía Muntu, dice que ahí caben las cosas y aquellas fuerzas que no poseen raciocinio (Sierra 27). Bien, ese vestido es un ejemplo preciso de Kintu, porque se convierte en una poderosa fuerza que reposa, de manera intangible, en una prenda de vestir que sirve de activador, de especie de canal ancestral que comunica con el pasado, y ese tiempo pasado es propio del Hantu, que refiere al lugar y tiempo; porque no es solamente el tiempo de los esclavizados, sino la atemporalidad de las heridas que se recrean en el espíritu la que se despierta cuando encuentra el canal conductor apropiado. Además, se reviste de la belleza, Kuntu, de la que estaba revestida Xica da Silva en el momento de operar con el traje.

Afirma Zapata Olivella que "el Muntu concibe la familia como la suma de los difuntos (ancestros) y los vivos, unidos por la palabra a los animales, los árboles, los minerales (tierra, agua, fuego, estrellas), y las herramientas, en un nudo indisoluble" (362). Ahora bien, pensemos en que el vestido fue una herramienta utilizada por Xica da Silva para poseer a sus amos, seducir a la sociedad blanca y poder incorporarse a ella. Si seguimos la premisa de Muntu planteada por Zapata Olivella, en el vestido hallamos un objeto que puede reconstruir el nudo indisoluble con la ancestralidad. ¿Pero qué se necesita para que sea posible esa recuperación de la memoria de Xica da Silva? Un rito.

Luego de la primera vez que usa el vestido, Fe empieza a experimentar un deseo incontrolable, místico, mágico, de ponérselo nuevamente, probárselo. Si el uso del vestido se redujera a una sola ocasión, no habría lugar para hablar de rito, pero en la novela se nos revela 
cómo Fe hace de esto un acto ritualizado que le despierta un desaforado deseo sexual, ligado con una necesidad de sentirse poseída por su amante, pero, además, violentada en el acto sexual, convirtiendo el sadomasoquismo en un nuevo y enfermizo placer. La autora planta las bases que hacen posible la ritualización. Primero va la sangre:

El día antes de su partida, la museógrafa regresó a solas a ese ático. Contempló por horas las amplias faldas del traje. Paseó las manos por las mangas que partían de su talle corto, bordado en oro. (...) Por debajo, Fe descubrió que el traje se sostenía por un complicado arnés de varilla y cuero. Las varillas estaban expuestas, su alambre corroído levantaba crestas de herrumbre filosa. Por ellas, también, Fe pasó sus manos. Las cortó el arnés. Corrió la sangre entre las palmas, por los dedos. El cuero frío se bebió el líquido rojo, gota a gota, y se tensó, como si recobrara una esencia primigenia que hacía tiempo echaba de menos (Santos-Febres 25).

Varios rituales de las comunidades negras de la diáspora africana implican la sangre ${ }^{7}$ como elemento que abre el diálogo con el ancestro difunto; la sangre como una especie de pequeña muestra de la conexión sanguínea con un árbol genealógico. Lo que aquí aparece como una cortadura casual que le produjo el arnés del vestido a Fe Verdejo es, en realidad, la sangre que sella el pacto que hace posible que recobre la esencia primigenia que hacía tiempo echaba de menos. Pero Mayra Santos-Febres no se queda apenas en la sugerencia de la sangre como símbolo de iniciación del ritual, sino que, además, lo explicita más adelante cuando detalla la reacción que tuvo Fe ante el hecho que acontecía:

Respondiendo a un impulso, Fe sorbió despacio el resto de su sangre. Su intención inicial era no manchar el traje. Sin embargo, se encontró disfrutando del sabor de sus rasgaduras. Tenue ardor sobre la piel, líquido pastoso y cálido. Alivio. Se alarmó y no quiso pensar en lo que hacía (25).

\footnotetext{
7 Por ejemplo, en la santería cubana, para realizar una ceremonia de invocación al orisha Changó, se ofrenda algo "semejante a la gallina (...) y se cree que, al matar estos animales, continúan viviendo incluso después de su muerte" (Riley 50).
} 
Es el primer momento en que se nos refiere a una Fe que disfruta del ardor sobre la piel, de sus rasgaduras; una Fe que sorbe su propia sangre y, al alarmarse, prefiere no pensar en lo que hace. Una Fe que aún responde al impulso. Aquí, el misticismo, la magia y la imaginería han quedado sembradas en un cuadro que exhibe el encuentro íntimo entre Fe y el vestido, cuyo trasfondo es posibilitado bajo la multiplicidad de representaciones espirituales que aloja la filosofía Muntu. Es decir, desde de la cosmovisión Muntu, se ha efectuado "un encuentro posible". En esta perspectiva, la experiencia de atraviesa Fe es comprensible como una práctica propia del Muntu. Sin embargo, aún no pasamos a verla siendo poseída a través del vestido. Más adelante llegará ese momento cuando el ritual se desarrolla completamente.

La famosa exposición "Esclavas manumisas de Latinoamérica" abrió sus puertas la primera semana de noviembre. Pero, en la Víspera de Todos los Santos, mientras afuera el gentío se disfrazaba para ir a celebrar la fiesta que nos legaron los paganos, Fe se quedó supervisando los últimos detalles del montaje. Ya todos se habían ido, me contó aún tirada en el suelo. Comenzó a revisar el maniquí que exponía el traje de la esclava. No se pudo contener. Se desnudó, allí, a solas, en las asépticas salas del museo del seminario. Desvistió el monigote. Se deslizó dentro de las telas. Se calzó las medias caladas y las ligas. Le quedaron exactas. El arnés de correas y varillas descansó punzante sobre su piel. Lo más difícil fue ajustarse el pasacintas de seda que tejía su prisión sobre el vientre, pero lo logró. Entonces, bajo aquel disfraz, la museógrafa Fe Verdejo se tiró a la calle y no regresó al seminario hasta la madrugada, con la piel hecha un rasguño y un ardor. Aquel fue el primer día de su rito (Santos-Febres 26).

En primer lugar, la exposición que montó Fe Verdejo y en la que estaba incluido el vestido era sobre esclavas manumisas, por lo que se debe comprender que, si hablamos de posesión, el tipo de espíritus que podrían usar el vestido objeto-herramienta, para poseer el cuerpo de Fe, es el de las esclavas que alcanzaron su libertad. Ahora bien, antes mencioné la recuperación de la memoria ancestral a través del rito. ¿De qué parte de la memoria (o clase de esta) estoy hablando? La que se recupera es la de las esclavas que modificaron sus condiciones de vida a través de su cuerpo. Una especie de "conquista», si se me permite, en la que el deseo del dominador se usó como "arma», siendo el cuerpo de las desposeídas el territorio de lucha. Al mismo tiempo, incluye la memoria de dominación y sumisión, llena de 
agravios, abusos, violaciones y violencias contra la mujer esclavizada. La autora pone lo anterior en la figura clave de Xica da Silva, pero propone el vestido como objeto que simboliza esta tortuosa memoria ancestral, con un propósito que se nos revela al final de la obra, pero no lo abordaremos aún.

Me interesa en este momento citar a Odette Casamayor-Cisneros, quien, en su artículo "Cuando las negras se desnudan: la experiencia inasible del cuerpo caribeño y afrodiaspórico en la creación plástica de María Magdalena Campos-Pons y la narrativa de Mayra Santos Febres (2015)", propone un interesante análisis de la relación que tiene el cuerpo de la mujer negra como alojamiento de memoria y campo performativo a través del cual se recrean, cargan y transforman vivencias ancestrales. Antes planteé interrogantes alrededor de las razones por las cuales Fe estaba «habilitada», por decirlo de alguna manera, para realizar el rito. A continuación, los responderé. ¿Por qué no cualquier persona puede contactarse con los ancestros difuntos a su antojo? y, nuevamente, ¿por qué no es coincidencia que sean las monjas quienes le hayan dado el vestido que a posteriori significó la creación del rito?

La protagonista de Fe en disfraz se forma dentro de este tipo de círculos de violencia anecdótica (la historia de las esclavas maltratadas que estudia, la de Xica da Silva (...), y finalmente las historias de la propia Fe Verdejo, su madre y su abuela, (...) violadas y abandonadas por hombres blancos). Como constancia de su condición, signada por las violencias de la historia, su cuerpo negro permanece. El cuerpo no es un traje que Fe Verdejo pueda cambiar según las circunstancias. Tanto las primeras dueñas del famoso traje como la abuela y la madre de Fe intentaron en su tiempo 'disfrazarse' de mujeres diferentes a las negras poseídas y forzadas por hombres blancos, que en realidad fueron". (Casamayor-Cisneros 145-146).

Con base en lo anterior, podemos percibir cómo el vestido se presta como instrumento para crear el disfraz con que se pretende abandonar la condición de poseídas y violadas por hombres blancos. A las mujeres que investiga Fe esto les sucedió, y también en la historia personal de ella, como ya lo indiqué. Fe Verdejo no es "cualquiera», es la conductora adecuada para el ritual. En su pasado se registra el resultado del proceso de violaciones de las que fueron víctimas quienes la antecedieron. Por eso Fe puede recuperar la memoria, por eso puede reciclarla y, posteriormente, intentar destruir el dolor en un acto simbólico. Puede ser poseída 
por la memoria que habita en el vestido, porque ella misma forma parte de esa memoria. Necesita de la sangre para que se active el conducto con la suya. Eso hace posible el ritual. Ahora bien, si volvemos al momento cuando Fe usa el vestido y se va, nos situaríamos en la fiesta del día de los muertos, lo cual tampoco es coincidencia, porque esta celebración pagana rinde tributo a los muertos concibiéndolos como parte del presente, como miembros activos del hoy de quienes les rinden tributo, y dicha celebración está en consonancia con el Hantu, pues el tiempo y lugar para referirse a la ancestralidad forma parte de la filosofía Muntu.

Paso a adentrarme en la revisión de tres aspectos de la obra. El primero es la elección de Xica da Silva como símbolo que representa el pasado de erotización y violencia de la mujer; posteriormente, me referiré al rol que cumple Martín Tirado, su asistente, como hombre blanco que se hace partícipe del ritual; finalmente, demostraré por qué es un ritual y qué busca la novela con el uso del vestido, aspecto que se revela al final, como anticipé.

Xica da Silva representa uno de los estándares de los que se ha servido Brasil para defender su supuesta armonía racial. Aún en nuestros días en este país, como en Cuba, se pretende defender una idea de mestizaje que define a las personas bajo una perspectiva que recoja una identidad totalizante resumida en la denominación "brasileños/as", más allá de las etnias y características culturales que cada grupo posee. En el caso de Xica da Silva se ha construido a través de ella una relación mítico-histórica que, por un lado, se sirve de su historia de ascenso social al casarse con un rico explotador de diamantes para introducir la erotización en su relato; Xica da Silva ha servido en Brasil para sostener la idea que las mujeres esclavizadas tenían un deseo sexual incontrolable, evidente falsedad. Por otro lado, ha servido como referencia para hablar sobre el declive del sistema esclavista a causa de las relaciones afectivas entre blancos libres poderosos y negras esclavizadas y/o libertas. Sin embargo, también es necesario mencionar que en este tipo de relaciones las mujeres negras nunca alcanzaban el rango de esposas, no eran presentadas en sociedad, sino que seguían siendo subalternas, amantes que se mantenían escondidas, esto significaba una doble explotación tanto racial como sexual (Valladares-Ruíz 601).

Xica funciona en el relato como el símbolo a través del cual se ha construido una relación entre la explotación, las pretensiones de ascenso y el «blanqueamiento» racial desde la época de la esclavitud. Desde la filosofía Muntu, es posible que la representación espiritual de Xica y 
los otros espíritus de mujeres sin nombre sometidas al abuso de los esclavizadores despierten y se contacten con Fe, una negra contemporánea interesada en comprender los porqués de esa situación que ellas y, de alguna forma, las mujeres más cercanas en su propia genealogía, vivieron. Eso da pie para formularse un interrogante: ¿Para qué Fe recupera esta memoria de tantas violencias?, ¿cuál es su fin? Más adelante responderé a esta pregunta de fundamental interés.

Martín Tirado es muy importante en la historia, pues, además de ser un testigo de primera mano de las transformaciones de Fe Verdejo, es su asistente y, por si fuera poco, es quien narra. Es decir, una mujer negra tiene como asistente a un hombre blanco. Eso representa una primera inversión de valores alrededor del poder étnico-racial y, por supuesto, de género. A lo anterior, se debe agregar que es su amante y cumple las órdenes de dominación sexual que indica Fe con el propósito de recibir placer, bajo el efecto de la posesión (más adelante me referiré al acto de posesión que sufre Fe Verdejo en el momento de usar el vestido), lo cual significa una segunda inversión de roles de dominación. Al respecto, Patricia Valladares Ruiz se refiere de manera muy clara en su artículo "El cuerpo sufriente como lugar de memoria en Fe en disfraz (2009) de Mayra Santos-Febres (2016)":

Mientras que "Fe Verdejo pagaba en sangre el placer de dar placer", Martín, por su parte, descubría el placer de dominar sexualmente a su amante: "Su sumisión me levantó un dragón por dentro. No pude evitar preguntarme si ese dragón era yo, si el de mentira era el otro Martín Tirado". En primera instancia, el dolor se presenta como una consecuencia directa de la búsqueda del gozo sexual, pero también como la representación y apropiación del sufrimiento de los ancestros de Fe (601).

En efecto, este rol de Martín es también el de autodescubrimiento de un placer de dominación sexual por parte del hombre blanco, que también es él. También se presenta en él una participación activa dentro del tejido del relato, pues, mientras Fe Verdejo "presta» su cuerpo para que a través de este se liberen las memorias que aloja el vestido, Martín se convierte en sí mismo en el co-ejecutor de este acto de dominación, de sufrimiento, pero también de liberación. Se apropia del cuerpo de Fe y le produce heridas que revitalizan la relación ancestral mediante el vestido-objeto-herramienta ritual. 
Pensemos en el Muntu como categoría y recordemos que se refiere a "persona», más que al simple término "hombre», pues este generalmente está ligado con la corporeidad, mientras que el término "persona» involucra aspectos que trascienden el plano corporal (Sierra 38), y esto posibilita que el género no sea un determinante para saber si se puede o no acceder a la fuerza vital en la filosofía Muntu. Si pensamos en el proceso de esclavización de pueblos negros africanos, los blancos colonizadores, en su afán por romper las ligaduras con la cultura de quienes estaban siendo esclavizadas, desarrollaron todo tipo de estrategias de separación, destierro y destrucción de los lazos que para ellos eran perceptibles. No obstante, el de la fuerza vital es intangible; razón por la cual, en sus actos de despojo, ese mismo hombre blanco estaba generando unas nuevas condiciones para que germinaran expresiones culturales transformadas y transformadoras, capaces de mutar durante la confrontación al encontrar maneras de comprender el mundo. Por eso Martín Tirado en la novela funciona como hombre blanco que integra el ritual a través del cual Fe Verdejo puede entrar en contacto con las fuerzas ancestrales. Fe necesita de ese «hombre blanco que violenta» para poder realizar el llamamiento de las violentadas por hombres blancos. Martín es instrumentalizado en el acto, un miembro del ritual.

¿De qué manera tiene lugar la posesión espiritual? En el pensamiento Muntu se habla de una memoria que está alojada en elementos físicos y no físicos. Hay rituales que permiten activar esa memoria mediante la consulta a los ancestros. Además, los difuntos son parte fundamental de las familias, de las comunidades, a ellos se les piden consejos, se les hacen ruegos, se les crean altares y se les rinden tributos. Un ejemplo de esto es la santería ${ }^{8}$ cubana, una especie de «negociación», realmente un ocultamiento ante el mundo católico de las bases de la religión yoruba (originaria de lo que hoy es Nigeria), en la que existen prácticas para evocar espíritus que puedan poseer los cuerpos de los vivos. Hay un babalawo ${ }^{9}$ o maestro de ceremonia que es quien ha sido designado por los orishas ${ }^{10}$ como conector entre el mundo de

\footnotetext{
${ }^{8}$ La santería es el término o nombre con el cual se identifica a las creencias yorubas que se fueron formando en Cuba con la doctrina católica, hasta formar lo que muchos estudiosos llaman hoy sincretismo religioso (Llorens 103-104).

- Ser babalawo significa obtener el rango más alto que pueda alcanzar un hombre en santería. Babalawo significa "padre de la adivinación" (Llorens 240).

${ }^{10}$ Orishas son las deidades del panteón yoruba. "El panteón yoruba es muy complejo y cada deidad simboliza una parte de la naturaleza. Cada deidad nace para ayudar al hombre a enfrentarse con esa parte de la naturaleza que la deidad domina, es por tal razón que el hombre le ofrece sacrificios para conseguir de éstos su ayuda y protección" (Llorens 122).
} 
los vivos y los muertos, quien realiza el rito en que se ofrece al orisha el cuerpo de alguna persona para que este pueda poseerlo y participar de una fiesta en homenaje al espíritu; beber con las gentes, danzar y entregar consejos o advertencias.

Fe - conocedora de estos antecedentes y desatendiendo las recomendaciones de la monja - se apropia del traje y hace de él un lugar de memoria, para decirlo en palabras de Pierre Nora. (...) (Para efectuar el ritual) Esto es posible apreciarlo en las narraciones de los encuentros sexuales entre Fe y Martín. Estos ocurren entre el 31 de octubre y el 1 de noviembre, fechas que coinciden con la fiesta de Samhain, además de otras celebraciones como Halloween, el Día de Todos los Santos y la víspera del Día de los Fieles Difuntos (Valladares 601).

En Fe en disfraz asistimos al desarrollo de un rito, pues tiene un procedimiento ritualizado de despojo de vestiduras y posesión de otras. Como se resalta en la cita anterior, tiene lugar durante un periodo particular ligado a festividades paganas relacionadas con homenajes a los muertos. Con esta invocación a todos los santos, a los muertos que usaron este vestido, la prenda se convierte en una especie de altar al que asciende Fe para ofrecer su cuerpo como lugar para el descenso de los espíritus. No la posee el vestido, la poseen los espíritus encerrados en la memoria que se abre con la sangre de Fe y el parsimonioso ritual al ponérselo. Fe, con el vestido puesto, es ella, pero también Xica da Silva, y la memoria ancestral de abusos, violencia sexual, dominación y resistencia. Este es un rito para despertar la memoria, para activarla. La sangre, el sudor y el cuerpo negro de Fe Verdejo son un conector eficaz para la posesión espiritual.

Es un ritual. Un acto amatorio ritualizado, una ceremonia de invocación espiritual. ¿Y el vestido? Las monjas reconocían en él poderes mágicos asociados al dolor de sus portadoras, al tal punto que, al entregárselo, le advierten a Fe que no debe ponérselo nunca (para ese entonces ya se lo había puesto), añadiendo que "los arneses y la tela han bebido demasiado sudor y demasiadas penas" (Santos-Febres 77); es decir, eran conscientes de que en él estaba alojada una memoria de sufrimientos. La fuerza vital del Muntu, revitalizada y transgresora, aguardando el instante para renacer.

En el vestido, el ritual de posesión, el descenso de los espíritus y la posterior destrucción del objeto, hay una intención liberadora. De recuperación de la memoria, sí, pero también de 
liberar a Fe Verdejo del peso de esta. Esta idea es compleja si se comprende que la memoria existe en tanto hay quien la recrea. Sucede que Fe Verdejo, una investigadora del siglo XXI que se ha labrado un camino a punta de inteligencia, capacidad de desarrollo intelectual y persistencia, tiene derecho a tener en su memoria algo más que la crueldad que padecieron las suyas. Entonces, ella ofrece su cuerpo como campo de batalla en el que se libran luchas llenas de un pasado sufriente, frustradas pretensiones de ascenso social, historias de posesión, dominación y violencia. Ella se presta para que, de una vez por todas, su cabeza pueda respirar un nuevo aire y se alimente de algo más que dolor. Paradójicamente, el dolor del que se quiere liberar necesita sufrirse. Necesita padecer el dolor para salir del dolor. Por eso luego pedirá ser liberada. Y así se cierra. No con un proceso de borrado histórico, sino con una revaloración de lo vivido, una reinterpretación que desde la filosofía del Muntu resulta posible y, si se quiere, sanadora. El acto de escucha de los gritos del pasado y la revelación de una actualidad necesitan de referencias para construir un sujeto que se pueda aferrar a una raíz. De esta manera se cierra:

Hoy es 31 de octubre, el tercero en que Fe Verdejo me convoca a devorarla y a dejarme devorar. A dejarme desdoblar. Sabía que llegaría este momento. Fe sabía que yo acudiría; que, de nuevo, me abandonaría a su rito ... Esta vez, cuando las diga, sacaré la navaja toledana. Sé que lo haré. Lo exige el rito. Lo exige el tiempo enquistado en el dolor de Fe, que ahora es mío ... La navaja en mis manos. Fe estará postrada contra el diván que contrastará, pálido, con su piel color madera chocolate. La desnudaré completa. Cortaré las telas de ese traje. Mi navaja rasgará el peplo, el pasacintas, destrozará las mangas y los holanes. Fe gritará, le taparé la boca. Entenderá que debo hacerlo; deshacerme de esa barrera que frena nuestro encuentro definitivo, duradero. Espero que no se resista demasiado... Y que, a sus pies, acepte el traje desgarrado. En la memoria de mi dueña, sonarán latigazos y carimbos. Se desvanecerán cicatrices y humillaciones. Entonces Fe, liberada, entenderá y se abrirá para mí. Ella misma lo ha querido. Me lo ha pedido todo este tiempo: "Rompe el traje, desgárralo, sácame de aquí" (Santos 113-115).

Es Martín el testigo que ha registrado toda la conversión, es el único que puede estar adentro del rito sin padecerlo en carne propia de manera directa. Desde su rol de amante, de seguidor, asiste al mismo. La misma Fe sería incapaz de destruir el vestido, porque sus propias 
manos no pueden rasgar la memoria, pues cuando esta emana en su cuerpo ella es el canal conductor, ella es quien le permite al pasado cobrar vitalidad, está poseída y no puede desposeerse a sí misma. Entonces, Martín siente que el rito pide de él un rol activo, el de aquel que deberá cercenarlo. Pide acabarlo.

Conviene hacer una mención a un asunto que resulta problemático. El poder depositado en el hombre blanco. Bajo la perspectiva de la cosmovisión Muntu, no se prevé que sea un hombre blanco quien «libere» a la mujer negra, y a sus ancestros, de los vejámenes producidos por los ancestros de este hombre blanco. Quizá, y esto lo sugiero a modo de conjetura, si bien desde el pensamiento Muntu se hace posible la creación del rito, la destrucción del vestido por parte de Martín obedece a unas ideas de responsabilidades históricas. Una especie de ocupación de roles históricos donde el rol de Martín sería dar la puntada final para acabar con un acto realizado por quienes le precedieron. Tal vez la parte que le corresponde, de destrucción del vestido, tiene que ver con que, en su figura, se nos representa un pasado donde los blancos que le antecedieron aplicaban su voluntad a las mujeres negras; quiero con esto decir, la obligación de usar el vestido, impuesta por el esclavizador, se destruye a manos de quien, en el acto ritual, le representa. Lo anterior, sumado a lo que mencioné, es imposible hacerlo para la misma Fe, pues la fuerza vital y memoria que reposan en el vestido superan su propia fuerza. Sin embargo, sigue siendo esta no más que una conjetura que me atrevo a sugerir.

¿Para qué el vestido? No para contar una y otra vez el terror de la esclavitud, sino para recuperar la memoria, mirarla de frente e intentar transformarla, no permitir que el dolor sea toda ella, sino que también la memoria arroje luces hacia el futuro, pero sin hacer del pasado el presente. El vestido es el símbolo de lo vivido, es el disfraz de las falsas armonías raciales, de la fallida pretensión de un pacífico sincretismo religioso. En él está depositada una carga de memoria ancestral llena de dolor que no se pretende repetir, se revive para que haya consciencia de ella y, justamente, se pueda cortar, para no padecerla nuevamente jamás.

Concluyo. Lo que hace valiosa la lectura desde esta perspectiva es la posibilidad de comprender, a la luz de la literatura contemporánea, un concepto filosófico de tanta complejidad. El Muntu, con la multiformidad que lo integra, a saber, Kintu, Kuntu, Hantu y Muntu, resulta de difícil comprensión cuando se pretende ingresar a él desde la profundidad de cada variante. Un ejemplo de ello podría ser Changó, el gran putas, de Manuel Zapata Olivella, que es quizá la novela donde se ha desarrollado con mayor profundidad una revisión de la 
construcción del pensamiento de la matriz africana en las Américas. En Changó, el gran putas es posible rastrear todos los conceptos que aquí he referido; sin embargo, en el caso de Zapata Olivella, su obra se ocupa de relatar la historia del pueblo negro en las Américas. Ello se convierte en una propuesta cuya envergadura es amplísima, a tal punto que, además de poder hacer una revisión de cada variante del Muntu, también se puede revisar el mestizaje y la construcción de identidad relacionada con la consciencia de la herencia africana. Y eso solo por nombrar algunos temas.

En este caso, me propuse revisar apenas una parte del Muntu, analizar cómo en Fe en disfraz es posible comprender aquello que en este artículo se denomina la fuerza vital. En esta obra también podrían revisarse otros aspectos, por supuesto, pero mi atención estaba centrada concretamente en exponer cómo, mediante la ritualización del vestido de una exesclavizada, el posterior desarrollo de un acto de transferencia de la memoria ancestral y la propia destrucción del objeto, se puede percibir la filosofía de la fuerza vital en esta novela contemporánea. Mayra Santos-Febres aporta a la literatura de la diáspora africana una obra que propone una recuperación de nexos ancestrales, religiosos y culturales, en un marco ficcional, al tiempo que los actualiza. Así, construye un mundo contemporáneo en el que aún es posible comprender parte de la cosmovisión Muntu. No se queda en el mero hecho de contar una historia con prolijidad literaria, sino que la atraviesa con la propia condición de mujer negra incorporada a una raíz afrodiaspórica en la que el personaje que protagoniza el relato hereda cuanto relata.

La importancia de las ideas que aporta la cosmovisión Muntu, en este caso a través de la filosofía de la fuerza vital, radica en la posibilidad de comprensión que ofrece. Al tener como marco esta visión, es posible profundizar en el análisis de comportamientos que, desde otras perspectivas, podrían padecer de interpretaciones erróneas o reduccionistas, que podrían calificar de «sadomasoquismo» o «perversión sexual». Lo que acá tiene otras significaciones, lo que acá es un rito que honra la memoria ancestral y se pretende como su puesta en escena, puede ser entendido como algo demoniaco y pagano. Significados que se pueden percibir al hacer una lectura desde otras fuentes de interpretación. Por eso es valioso que la literatura contemporánea se nos presente también como un lugar posible para la comprensión de estos elementos. Esa es la razón por la que me he propuesto revisar estas conexiones históricas y filosóficas. No pretendo entregar novedades, sino ofrecer posibilidades. Cumple su propósito 
este artículo si suma al goce lector que produce esta excelente obra, la oportunidad de comprenderla desde otros horizontes, y entender con ella otras formas de pensamiento.

\section{Referencias}

Banguero, Rigoberto y Valerie Gruber. El Muntu afrodiaspórico en el mundo-vida del Chocó (Colombia). Santiago de Cuba: XIX Conferencia Internacional de Cultura Africana y Afroamericana, 2020. Inédito. Impreso.

Barriga Monroy, Martha Lucía, y "La historia del tambor africanoy su legado en el mundo." El Artista, vol., no. $1, \quad 2004, \quad$ pp.30-48. Redalyc, https://www.redalyc.org/articulo.oa?id=87400104. Digital.

Casamayor-Cisneros, Odette. "Cuando las negras se desnudan: la experiencia inasible del cuerpo caribeño y afrodiaspórico en la creación plástica de María Magdalena CamposPons y la narrativa de Mayra Santos Febres". Cuadernos de Literatura. Dic. 2015: 137158. Digital.

Gómez García, Pedro. "Mediadores e intermediarios: sacerdotes, brujos y santones". Religión y cultura. Ene. 1999: 29-44. Digital.

Llorens, Idalia. "Sincretismo religioso: pervivencia de las creencias yorubas en la isla de Puerto Rico". Memoria presentada para optar al grado de Doctor. Universidad Complutense, 2003. Digital.

Riley, Ellis. "La comida y los Orishas de Santería: alimentando el bienestar de los creyentes". Tesis de maestría. Universidad de Colorado, CSU Theses and Dissertations, 2015. Digital.

Ruiza, M., Fernández, T. y Tamaro E. (2004). "Biografía de Chica da Silva”. Biografías y Vidas. La enciclopedia biográfica en línea. 2004 $<$ https://www.biografiasyvidas.com/biografia/s/silva_chica.htm>. Digital.

Santos-Febres, Mayra. Fe en disfraz. Puerto Rico: Alfaguara, 2009. Impreso.

Sierra Díaz, Diana. "El Muntu: la diáspora del pensamiento filosófico africano en Changó, el gran putas, de Manuel Zapata Olivella”. Revista La Palabra. Jun. 2016: 23-44. Digital.

Valladares-Ruiz, Patricia. "El cuerpo sufriente como lugar de memoria en Fe en disfraz, de Mayra Santos-Febres". Cuadernos de Literatura. Oct. 2016: 595-616. Digital. 
Zapata Olivella, Manuel. La rebelión de los genes: El mestizaje americano en la sociedad futura. Colombia: Altamir Ediciones, 1997. Impreso. 